\title{
Evaluation of Mechanical Properties of Four Different Carbon/Epoxy Composites Used in Aeronautical Field
}

\author{
Jane Maria Faulstich de Paiva ${ }^{\mathrm{a}, \mathrm{b} *}$, Sergio Mayer, Mirabel Cerqueira Rezende ${ }^{\mathrm{a} *}$ \\ a'Divisão de Materiais, AMR/IAE/CTA, Centro Técnico Aeroespacial \\ Praça Marechal-do-Ar Eduardo Gomes, 50, 12228-904 São José dos Campos - SP, Brazil \\ ${ }^{\mathrm{b}}$ UNISAL, Centro Universitário Salesiano, Unidade de Americana - SP, Brazil \\ 'Departamento de Aeronáutica e Mecânica/ITA, Embraer, Empresa Brasileira de Aeronáutica, \\ São José dos Campos - SP, Brazil
}

Received: October 29, 2003; Revised: November 20, 2004

\begin{abstract}
Four families of carbon fiber reinforced composites (CFRC) used in aeronautical industry were evaluated by flexural and interlaminar shear tests. It is also characterized three families of non-conditioned and conditioned CFRC by compression test. The composites were obtained by hand lay-up process in autoclave by using prepregs based on epoxy matrices (F155 and F584) and carbon fiber fabric reinforcements (PW-"Plain Weave" and 8HS"Eight Harness Satin"). The F155-epoxy matrix was cured at $121{ }^{\circ} \mathrm{C}$ and the F584-epoxy type at $177^{\circ} \mathrm{C}$. After molding, the laminates were cut in specimens attending the ASTM D790 for the flexural test, the ASTM D2344 for the interlaminar shear test (ILSS) and the ASTM D3410 for the compressive test. The compressive tests were performed for testing the specimens before and after hygrothermal conditioning. The results show that the F584-epoxy matrix laminates present higher mechanical properties when compared to the F155-epoxy ones. The shear-tested samples observed by scanning electron microscopy and that ones tested in flexural, analyzed by stereoscopy, revealed that the fractured surfaces present typical aspects. The compressive results show that the hygrothermal conditioning caused the decrease of the compressive strength in, approximately, $8-20 \%$ depending on the laminate type. The failure modes of the tested specimens were evaluated showing good agreement with the literature.
\end{abstract}

Keywords: composites, carbon fiber, epoxy resin, mechanical strength

\section{Introduction}

Carbon fiber reinforced polymeric composites are very used in aeronautical industry to manufacture several components as flaps, aileron, landing-gear doors and others ${ }^{1}$. This material is named advanced composites of polymeric matrix (epoxy, bismaleimide, phenolic) reinforced with high-modulus or high-strength carbon fibers. In relation to the thermoset polymeric matrices, the epoxy resins are the most used to obtain these structural components because of their thermal, chemical, mechanical and corrosion resistances ${ }^{2,3}$.

Compared to metals, the polymeric composites have many advantages as higher fatigue strength, higher corrosion resistance and lower weight ${ }^{1,4,5}$. However, the aircraft components fabricated in polymeric composites present tight requirements in service and they can suffer mechanical damages during the utilization ${ }^{6}$. The damages can occur during the fabrication process, handle, transport, storage and maintenance ${ }^{6,7}$.

Polymeric composites are susceptible of mechanical damages when they are subjected to efforts of compression, tension and flexural, which can lead to interlayer delamination. In any cases, the increase of the external load favors the propagation of delamination through the interlayer leading to the catastrophic failure of the component ${ }^{8}$. Therefore, it is necessary to use materials with higher damage tolerance and to carry out an adequate mechanical evaluation of the materials before using in aircraft parts.

Damage tolerance of epoxy polymeric composites can be enhanced by improving the interlaminar properties by toughening the matrix and/or by using reinforcement with bi-directional arrangement of the tows (fabric) $)^{8}$. The objective of using fabric reinforcements is to take advantage of the thickness of arranged fibers to enhance both interlaminar and compressive strengths and also the toughness ${ }^{9}$. For

*e-mail: janepaiva@uol.com.br, mirabel@iae.cta.br

Article presented at the II SBPMat, Rio de Janeiro - RJ, 26-29/October/2003 the purpose of verifying the mechanical performance of polymeric composites different types of mechanical tests, as flexural, shear, and compression, are used.

Flexural and interlaminar shear strengths of continuous fiber reinforced composites are usually performed to characterize these materials due to the ease of specimen preparation and testing. Gripping, buckling and end tabbing are not issues for these type of tests ${ }^{10,11}$.

In flexural tests, beams with a small span-to-thickness ratio $(\mathrm{L} / \mathrm{h})$ are dominated by shear and beams with long spans fail in tension or compression ${ }^{10}$.

In general, the shear failure is affected by the same factors as the transverse tensile strength, because shear stresses and strains become concentrated in the matrix between fibers in a similar manner to that outlined for transverse tensile. However, there is more scope for local matrix deformation to take place, without occurrence of crack. Under shear stress, the local stress concentration is relaxed more readily ${ }^{12}$. The shear tests are used to evaluate both the interfacial adhesion fibers-matrix ${ }^{13}$ and the effect of binder on the composite mechanical properties, as fracture toughness and interlaminar shear strength ${ }^{14}$.

For composites the compression tests are designed to produce compressive property data for the material specifications, research and development ${ }^{15}$. This test is important because it helps to identify parameters that influence the compressive response of composite materials, as fiber and matrix types and fiber-matrix interface. These data can be used to study the relationship among textile preform architecture, type of matrix, mechanical properties and failure modes ${ }^{9}$. The presence of local defects, which are often difficult to characterize, also influences the failure in compression. 
Failure in compression is dependent on the way that the loading is applied. Usually, under axial compression, initially occurs the plastic deformation of the matrix followed by microbuckling that frequently evolves to kink zones, which can provoke the fiber buckling, and finally the formation of two planes of fracture. In this way, the composite material can fail under axial compression by macroscopic shear of certain planes ${ }^{12}$.

When components manufactured with polymeric composites are exposed to moisture and elevated temperature, mechanical damages occur faster ${ }^{16}$. The presence of water modifies the properties of the polymeric matrix and, consequently, the mechanical properties such as strength, stiffness, and creep ${ }^{17,18}$. So become important to evaluate the influence of moisture and temperature on the mechanical behavior, for example, on the compressive strength.

Considering the several environmental factors and mechanical stresses that can occur in structural polymeric composites, this work shows a systematic study involving these aspects. Flexural, shear and compressive strengths of two types of epoxy matrix (F155 and F584) reinforced with two types of carbon fabric (PW and 8HS) were evaluated. The main purposes were quality control, data evaluation and comparative testing. Failure modes of specimens tested under flexural and interlaminar shear were also determined and classified. Compressive failure modes were evaluated before and after hygrothermal conditioning. The used carbon fiber reinforced epoxy composites are in application in the Brazilian aeronautical industry.

\section{Experimental}

\subsection{Composite molding}

The prepregs were based on epoxy matrices (F155 and F584) and carbon fiber fabric reinforcements $\left(0 / 90^{\circ}\right)$, (PW -"Plain Weave" and 8HS - "Eight Harness Satin"). Figure 1 shows the fiber arrangements of the carbon fabric used to manufacture the laminates. In agreement with the supplier of prepreg ${ }^{19}$ the F155 type is a typical epoxy matrix and the F584 matrix was toughened with a thermoplastic.

The consolidation of the four laminate families (F155/PW, F155/ HS, F584/PW and F584/HS) in the autoclave was performed by using vacuum bags in metal molds (plates) under pressure of $0.70 \mathrm{MPa}$. For the F155 prepregs, it was used a cure cycle with a heating rate of $2.5 \pm 0.2{ }^{\circ} \mathrm{C} / \mathrm{min}$ up to $121^{\circ} \mathrm{C}$, holding at this temperature at least 90 minutes. For the F584 prepregs it was used a cure cycle with a heating rate of $2.5 \pm 0.2{ }^{\circ} \mathrm{C} / \mathrm{min}$ until $177^{\circ} \mathrm{C}$, holding at this temperature for a minimum of 120 minutes. All processed laminates presented
$60 \pm 1 \% \mathrm{v} / \mathrm{v}$ of carbon fiber reinforcement, determined according to ASTM D317121.

\subsection{Flexural tests}

The flexural tests were carried out in accordance to ASTM D790 (3-point loading $)^{11}$, using a minimum of ten specimens (dimensions: $80 \mathrm{~mm} \times 10 \mathrm{~mm} \times 4 \mathrm{~mm}$ ) for each laminate family. These tests were performed in a universal testing machine (Instron) at constant crossspeed of $1.7 \mathrm{~mm} / \mathrm{min}$, at room temperature, using an appropriate device for flexural test.

To calculate the flexural strength it was used the Equation 1:

F. S. $=3 \cdot$ P.L $/ 2 \cdot b \cdot \mathrm{e}^{2}$

where:

F. S. = flexural strength, $M P a$

$\mathrm{P}=$ rupture load, $N$

$\mathrm{L}=$ support span, $m$

$\mathrm{b}=$ width of specimen, $m$

$\mathrm{e}=$ thickness of specimen, $m$

\subsection{Shear tests}

The interlaminar shear tests (ILSS) were carried out in accordance to ASTM D2344 ${ }^{22}$, using at least ten specimens (short beam: $24.0 \mathrm{~mm} \times 6.35 \mathrm{~mm} \times 4.0 \mathrm{~mm}$ ) of each laminate family in appropriate device for shear test at universal machine (Instron). The calculation was based on Equation 2:

I.S.S. $=0.75 \mathrm{P}_{\mathrm{R}} /$ b.e

where:

I.S.S. = interlaminar shear strength, $M P a$

$\mathrm{P}_{\mathrm{R}}=$ rupture load, $N$

$\mathrm{b}=$ width of specimen, $m$

$\mathrm{e}=$ thickness of specimen, $m$

\subsection{Compressive tests}

The compressive tests were performed in accordance to ASTM D3410 ${ }^{15}$, using ten specimens (dimensions: $139.7 \mathrm{~mm} \times 12.7 \mathrm{~mm} \times 2-3 \mathrm{~mm}$ ) for each laminate family. For this test the specimens were prepared with tabs of fiberglass laminates. The tests were performed in a universal testing machine (Instron) at a constant cross-speed of $1.27 \mathrm{~mm} /$ min, using a type IITRI fixture (developed by Illinois Institute of Technology Research Institute) ${ }^{10,15}$. The specimens were tested at room

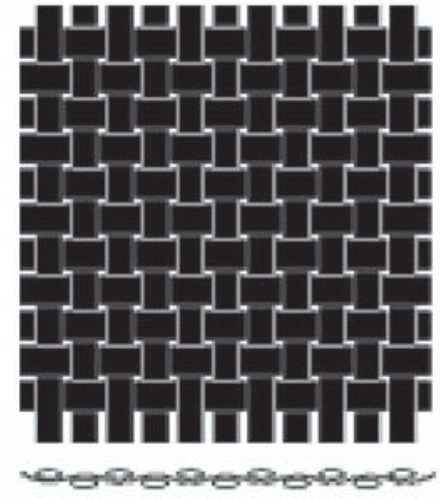

(a)

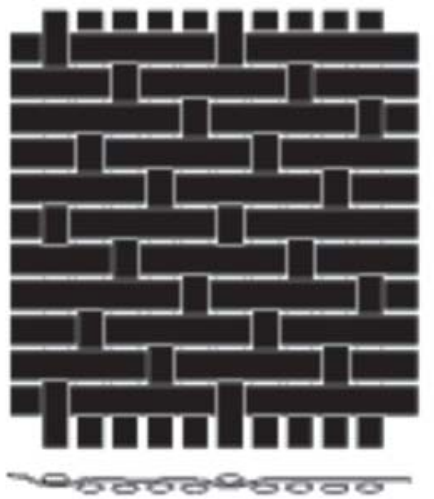

(b)

Figure 1. Types of carbon fabrics: a) plain weave (PW); b) harness satin (HS $)^{20}$. 
temperature before and after the hygrothermal conditioning.

The compressive strength results were obtained by using Equation 3:

$$
\text { C. S. = P / b.d }
$$

where:

C. S. = compressive strength, $M P a$

$\mathrm{P}=$ maximum load, $M N$

$\mathrm{b}=$ width of specimen, $m$

$\mathrm{d}=$ thickness of specimen, $m$

\subsection{Microscopic analyses}

After the mechanical tests, 4 specimens of each laminate family were analyzed by stereoscopy (Zeiss equipment, model Stemi SV11) to identify the failure mode occurrence.

Shear tested specimens were also analyzed by Scanning Electronic Microscopy (SEM) to evaluate the failure modes. It was used a LEO equipment, model DSM 435, with vpi (variable pressure) device.

\subsection{Conditioning of specimens}

The hygrothermal conditioning was performed at $80 \pm 5{ }^{\circ} \mathrm{C}$ and $90 \pm 5 \%$ of humidity for ten specimens of each family of laminate in a hygrothermal chamber (Climats), in accordance to ASTM D522923. The specimen's saturation (weight constant) was obtained after approximately 8 weeks. The water saturation it was measured approximately $2.8 \%$ for the F155 epoxy matrix laminates and 3.6\% for the F584 matrix ones.

\section{Results and Discussion}

Table 1 presents the flexural strength values of all tested laminates. Considering the standard deviation, it can be realized that the flexural strength values of the F155 laminates are close to one another. However, it can be observed a slight increase of the values for the F155-PW laminates. The F584/PW and F584/8HS laminates showed the highest flexural strength values. This behavior is attributed to the higher toughness of the F584 matrix, which was modified with a thermoplastic.

These better results show that the toughening of epoxy matrix with a thermoplastic polymer was adequate improving its mechanical property and probably its interface with the reinforcement. This result suggests that the used thermoplastic has high structural performance and good compatibility with epoxy and carbon fiber, improving consequently the interface among the components of the composite. Engineering thermoplastics used for toughening thermoset matrices need have high $\mathrm{T}_{\mathrm{g}}$ (glass transition temperature) and moduli. These requirements are necessary to not compromise the desirable properties of epoxy resin systems ${ }^{24}$.

Therefore, the prepreg supplier (Hexcel Composites) not reveals technical information about the formulation of polymeric matrix, as a tool to protect sales and market. In general, epoxy resins applied in aeronautical industry are based on DGEBA (diglycidyl ether of bisphenol-A) type with curing agent or hardener type 4,4'-diamino diphenyl sulfone (DDS ${ }^{14,25}$. Probably, modified epoxy involves a tri-

Table 1. Flexural strength of the laminates.

\begin{tabular}{lc}
\hline Composite & Flexural Strength (MPa) \\
\hline F155 / PW & $837.9 \pm 23.5$ \\
F155 / 8HS & $792.4 \pm 30.8$ \\
F584 / PW & $1288.5 \pm 45.4$ \\
F584 / 8HS & $1119.1 \pm 43.2$ \\
\hline
\end{tabular}

functional resin, as for example, tri-glycidil p-amino phenol modified with a thermoplastic type polysulphone of bisphenol-A (PSF) ${ }^{24}$.

The modification of epoxy resin with thermoplastics leads to good results because they toughen highly crosslinked resins more effectively than polymers with a low density of crosslinks. This type of toughened formulation is considered the state-of-art in epoxy systems $^{24,25}$.

Figures 2-5 show micrographs obtained by stereoscopy of the specimens fractured in flexure tests. It is observed that the laminates presented total failure in spite of the different arrangements of the warp and fill of the carbon fabrics.

Comparing the total fracture regions of the tested laminates with the required in the standard ASTM D790, it is observed a very good accordance, which make valid the performed flexural tests ${ }^{10,11}$.

According to Table 2, the shear strength values of the F155/PW and F155/8HS laminates are quite similar. These results indicate that the arrangement of carbon fabric did not affect the shear property of the F155 epoxy laminate.

Comparing the F155 and the F584 laminates (the latter matrix is modified with a thermoplastic) it is observed a significant influence of the matrix on the interlaminar shear strength. In this case, it is also verified that the F584 epoxy matrix reinforced with PW carbon fabric shows a slightly improvement on this property.

The molded laminates presented interlaminar shear strength values (Table 2) near to those reported by the prepreg supplier (approximately $70 \mathrm{MPa})^{20}$. In the same way, the literature ${ }^{1}$ presents similar interlaminar shear values for the unidirectional $\left(0^{\circ}\right)$ carbon fiber reinforced epoxy matrix composites, approximately $72 \mathrm{MPa}$.

The literature reports typical interlaminar shear strength values for aramid fiber reinforced epoxy matrix composites $(49 \mathrm{MPa})^{1}$ and for glass fiber reinforced epoxy matrix $(30-75 \mathrm{MPa})^{3}$. Despite the fact these composites are manufactured with different types of reinforcement and no consideration is made about the resin and the fiber-resin interface it is observed that the interlaminar shear strength values are in a range of 30 to $75 \mathrm{MPa}$. This behavior is characterized by the fact that the shear stress is concentrated in the matrix (epoxy resin) $)^{12}$.

Table 2. Shear strength of the laminates.

\begin{tabular}{lc}
\hline Composite & Interlaminar Shear Strength (MPa) \\
\hline F155 / PW & $63.9 \pm 1.8$ \\
F155 / 8HS & $63.5 \pm 3.5$ \\
F584 / PW & $84.8 \pm 5.2$ \\
F584 / 8HS & $72.2 \pm 4.8$ \\
\hline
\end{tabular}

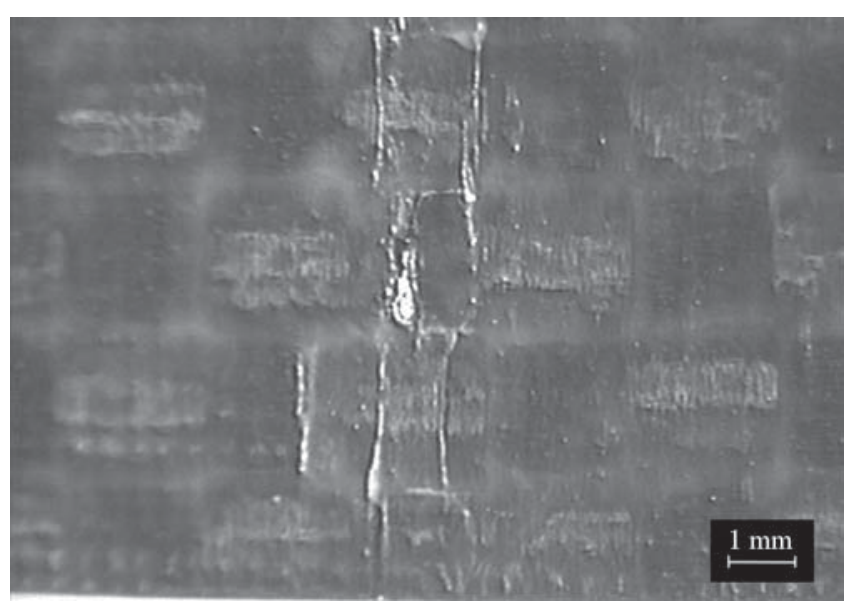

Figure 2. F155/PW laminate, specimen after flexural test, (8 x). 
Figures 6-8 show the SEM micrographs of the fractured specimens after the interlaminar shear tests. For all specimens it is observed a typical failure mode by shear, with the interlaminar cracking in the middle part of the transverse region of the specimen. This behavior agrees with the literature ${ }^{26,27}$, and makes valid the performed test because the standard demands that in this type of test the failure must reveal interlaminar failure.

Table 3 shows the compressive strength values for the F155 laminates and the standard deviations, which can be considered close.

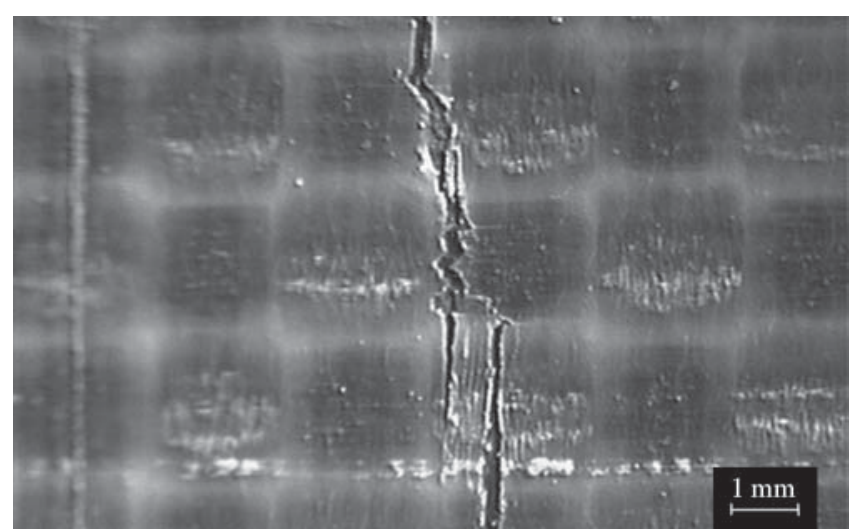

Figure 3. F155/PW laminate, opposite side of specimen after flexural test, $(8 \mathrm{x})$.

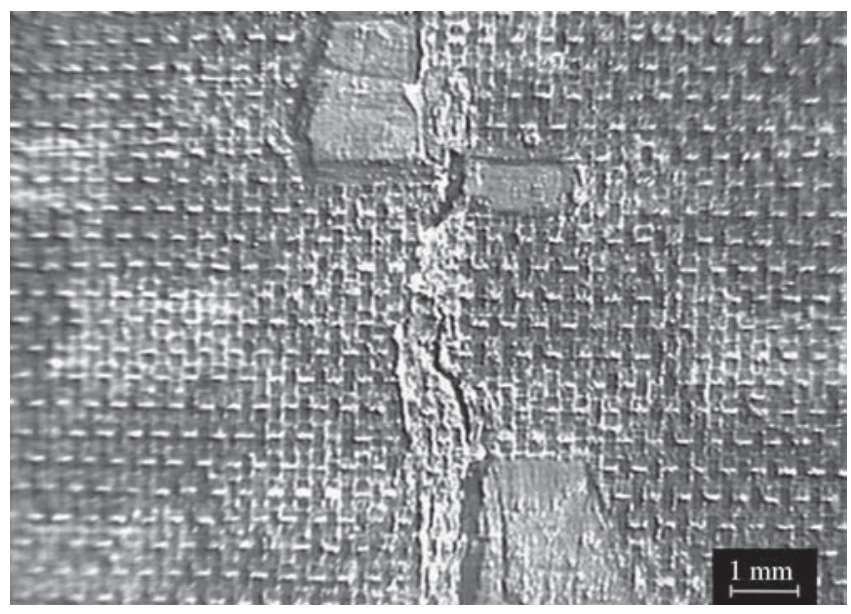

Figure 4. F155/8HS laminate, specimen after flexural test, (8 x).

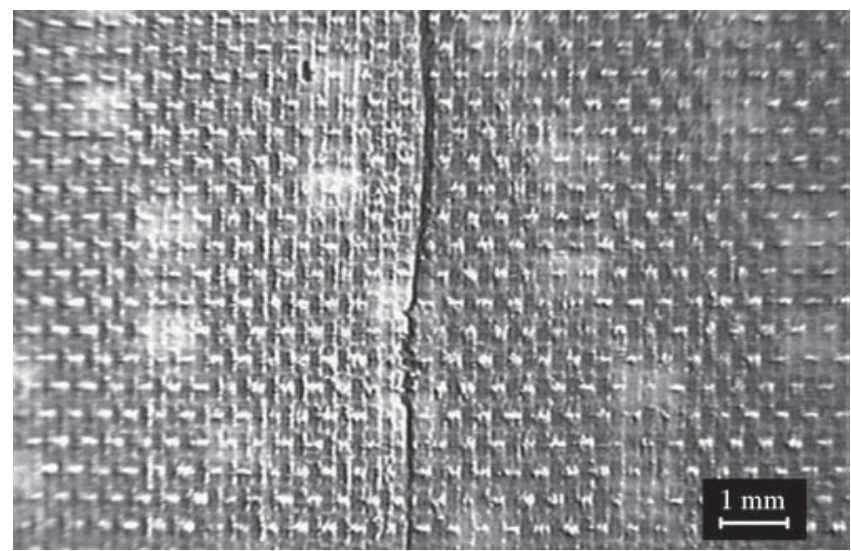

Figure 5. F155/8HS laminate, opposite side of specimen after flexural test, $(8 \mathrm{x})$.
The F584-epoxy based laminate presents the highest compressive strength, attributed to the modification of epoxy matrix by thermoplastic. This result shows that the use of thermoplastic modifier increased the fracture resistance of the epoxy system. Probably, this property is related to the formation of a second tough phase, which during the formulation of mixture is initially miscible in the epoxy resin, but it separates at some point during the cure to forming two phases, a thermoplastic rich phase and an epoxy rich phase. This type of modification produces multiphase morphology able to initiate

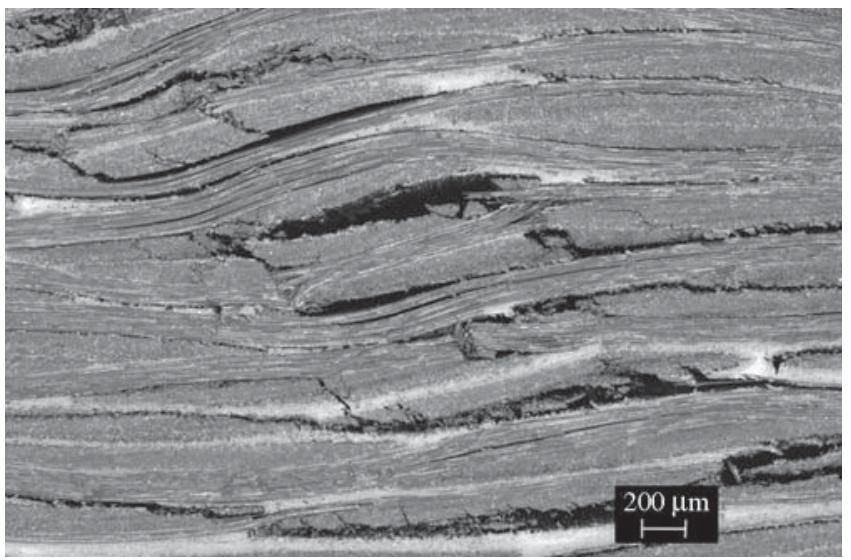

Figure 6. SEM of F155/PW laminate after shear test, $(30 \mathrm{x})$.

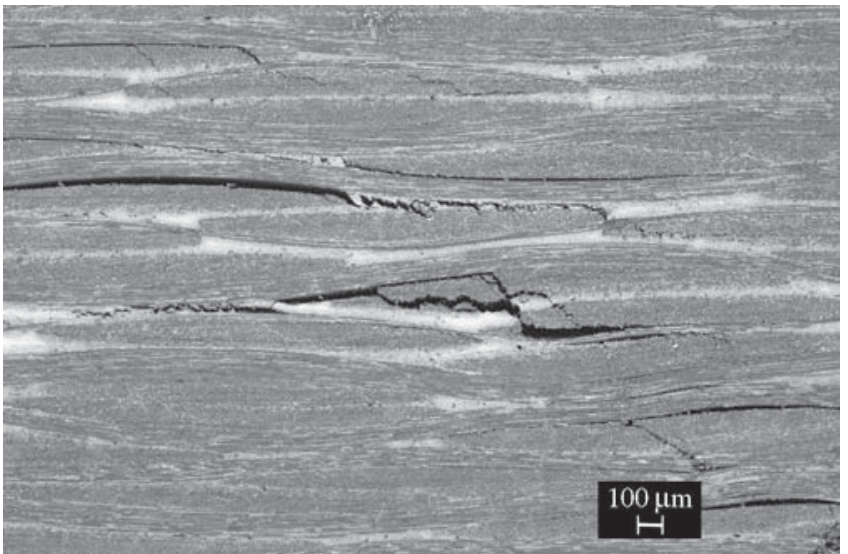

Figure 7. SEM of F155/8HS laminate after shear test, (30 x).

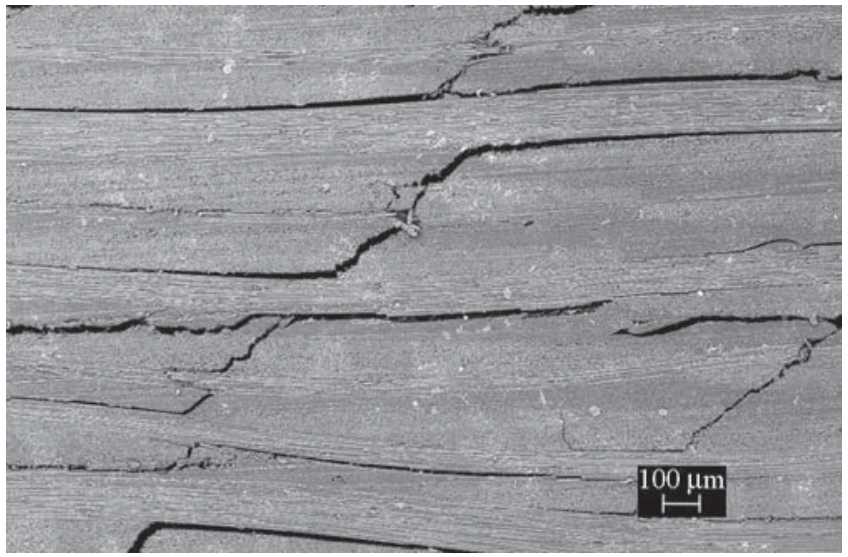

Figure 8. SEM of F584/PW laminate after shear test, (30 x). 
toughening mechanisms that dissipate energy of a propagating crack. This mechanism favors the toughness increase ${ }^{24}$.

The following figures (Figures 9-14) show conventional photographs of fractured regions of the tested specimens that present typical failure modes $^{10,12}$.

Figure 9 shows that the main failure mode occurred by shear involving the fracture in both matrix and fiber of the F155/PW laminate. For F155/8HS laminate (Figure 10) it is observed failure by shear and axial splitting ${ }^{10}$.In the case of splitting, the fiber/matrix interface splits during failure and the fibers are broken in the process ${ }^{28}$.

For the F584/8HS laminates (Figure 11) it is observed compression failure that started with the kink zone formation ${ }^{10}$ that propagated into the fracture. According to the literature ${ }^{29}$ it is also noted that the failure mode in the carbon-epoxy laminates under compression loading starts by shear involving the fiber kinking. The kinked fibers disrupt the stability of the neighboring fibers, which are also led to fail in kinking mode. This damage propagation process continues until the complete fail of the composite.

Table 4 shows the lower compressive strength values after the hygrothermal conditioning, due to the combination of moisture and temperature effects. The comparison of the compressive strength medium values of dry and wet tested specimens shows that occurred a decrease of approximately $7.7 \%$ for the $\mathrm{F} 155 / \mathrm{PW}$ laminates, $15.7 \%$ for the F155/8HS and 20.3\% for the F584/8HS respectively after the hygrothermal conditioning. It is also observed that the standard deviation increased for the F155 laminates, suggesting that this epoxy resin system was more affect by the hygrothermal conditioning.

The compressive failure loads can be significantly reduced if occurs reduction of the stiffness of the matrix, due to heating or, as observed for polymer matrices, to prolonged exposure to water ${ }^{12}$. High temperature and absorbed moisture can cause expansion and plasticization of the matrix, which can lead to degradation of the fiber-matrix interface, introducing residual stresses, changes of elastic modulus, cracking and delamination ${ }^{18}$.

In general, it is observed that all tested specimens present almost the same failure modes for dry and wet conditionings (Figures 11-14). However, it is observed in some cases that the failure modes were less severe for conditioned specimens than for non-conditioned ones. This behavior of the conditioned specimens is attributed to the plasticizing effect of the water into de polymeric matrix that contributes for decreasing the compressive strength values but providing a certain deformation before fracture.

The environmental effects caused by both elevated temperature and moisture can be reversible when the material is exposure under such conditions by a short period of time. However, the exposure for long period of time causes irreversible effects due to the interaction of water with polar groups of polymeric matrix. This phenomenon can provoke the decrease of physic-chemical interactions between fiber

Table 3. Compressive strength values of the laminates.

\begin{tabular}{lc}
\hline Composite & Compressive Strength (MPa) \\
\hline F155 / PW & $533.6 \pm 29.5$ \\
F155 / 8HS & $545.5 \pm 26.2$ \\
F584 / 8HS & $728.8 \pm 30.5$ \\
\hline
\end{tabular}

Table 4. Compressive strength values of the conditioned laminates.

\begin{tabular}{lc}
\hline Composite & Compressive Strength $(\mathrm{MPa})$ \\
\hline F155 / PW & $492.6 \pm 55.0$ \\
F155 / 8HS & $459.8 \pm 47.6$ \\
F584 / 8HS & $580.6 \pm 25.7$ \\
\hline
\end{tabular}

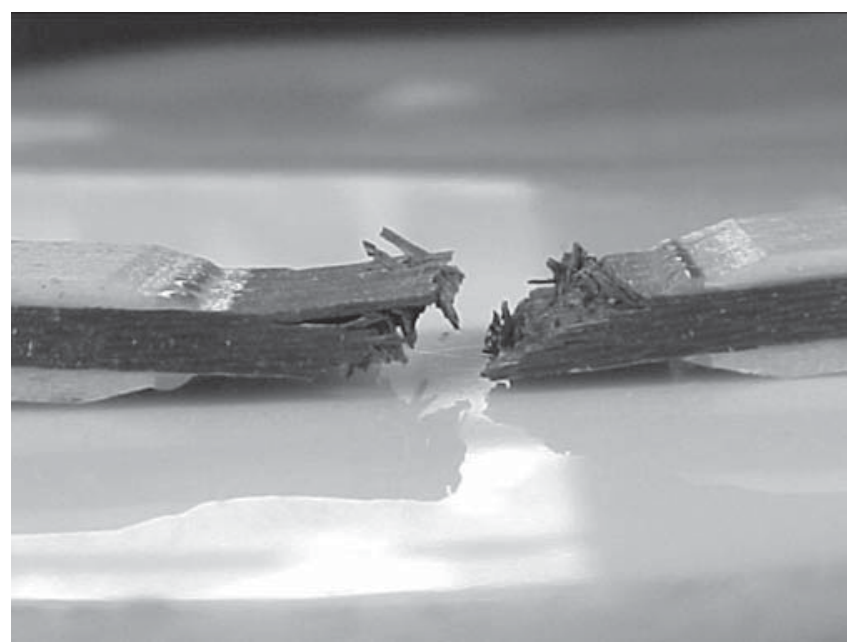

Figure 9. F155/PW laminate after compression test showing "shear failure" type.

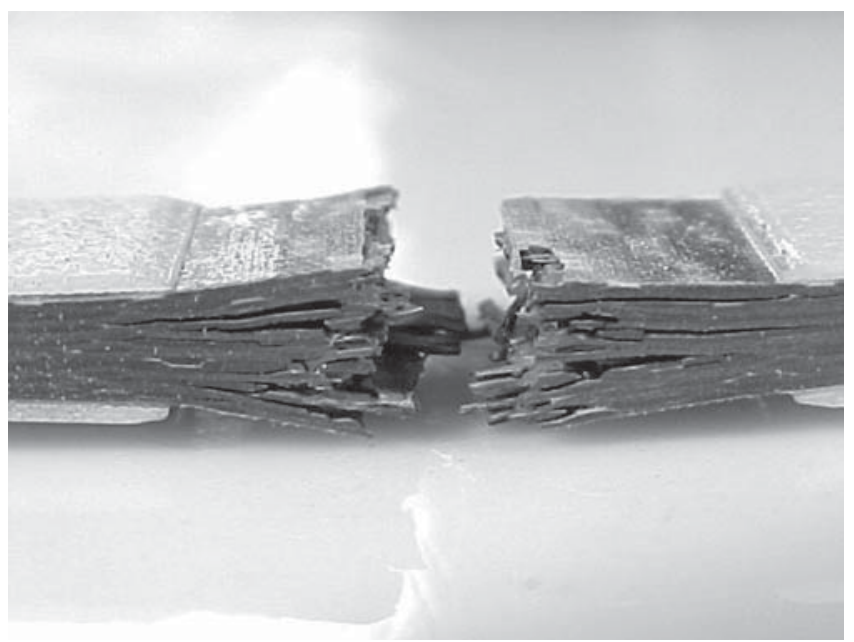

Figure 10. F155/8HS laminate after compression test, showing "axial splitting" fracture.

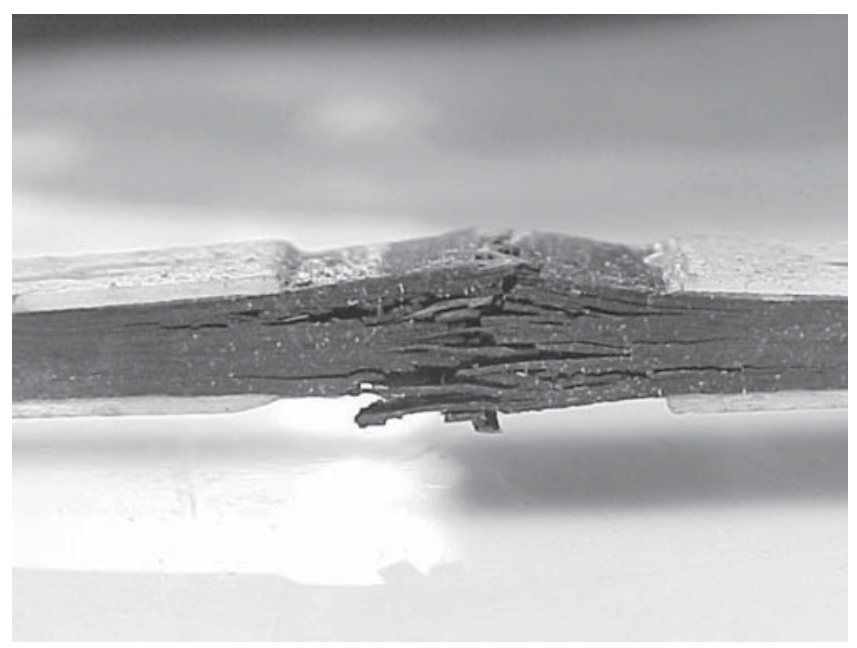

Figure 11. F584/8HS laminate after compression test, showing "kink zones" and fracture. 


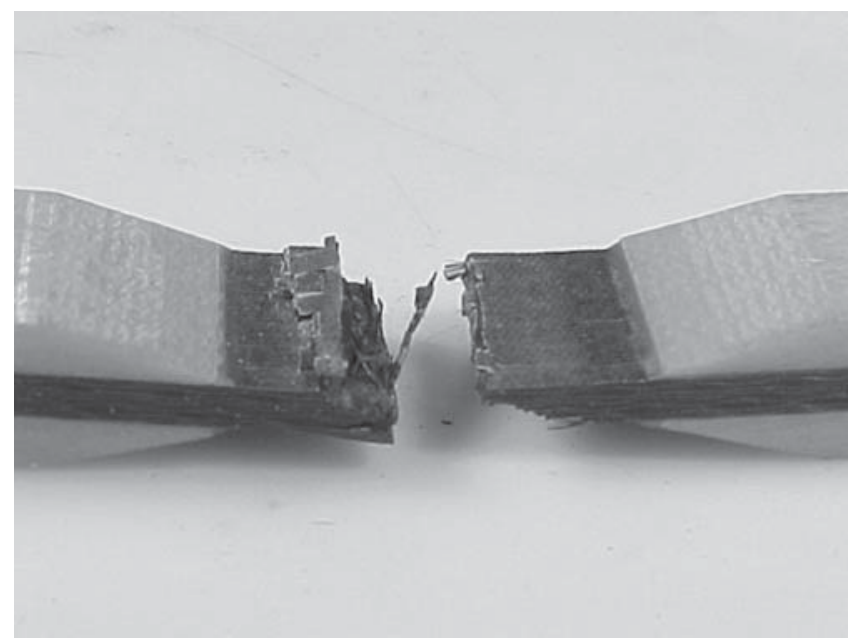

Figure 12. Conditioned F155/PW laminate after compression test, showing "shear failure" type.

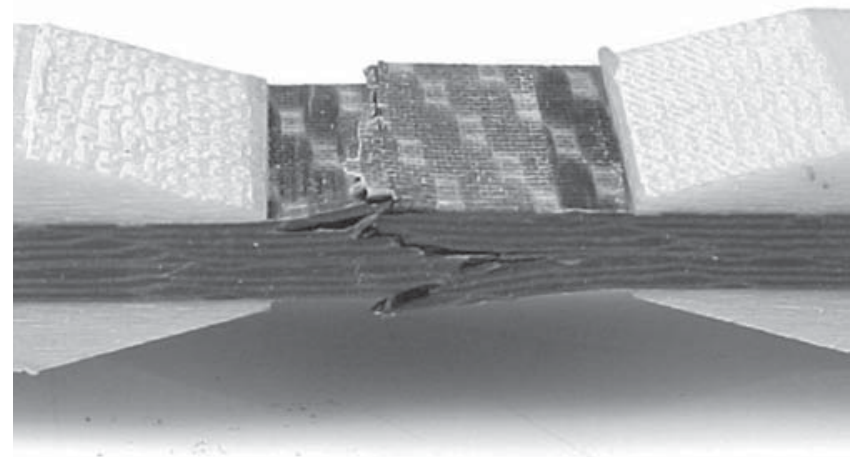

Figure 13. Conditioned F155/8HS laminate after compression test, showing "shear failure" type.

and resin, which leads to interface degradation and consequently the mechanical properties decrease ${ }^{12,16,17,30,31}$. In this work, it is observed the total failure of the tested laminates.

\section{Conclusions}

In general, the flexural and shear tests showed that the matrix type caused greater influence on the mechanical properties than the carbon fabric arrangement type. The F584/PW and F584/8HS laminates showed the highest flexural strength values than the F155 epoxy ones. This behavior is attributed to the higher toughness of the F584 matrix, which was modified with a thermoplastic, suggesting that the toughening of the epoxy matrix improved its mechanical property and probably its interface with the reinforcement. All tested laminates showed the occurrence of valid failure modes according to those presented in the literature. For all compression-tested laminates the failure mode occurred in the central region of the specimens according to the expected ones.

After hygrothermal conditioning the specimens presented failure modes similar to the non-conditioned ones, but the failures were less severe confirming that the wet samples suffered the plas-

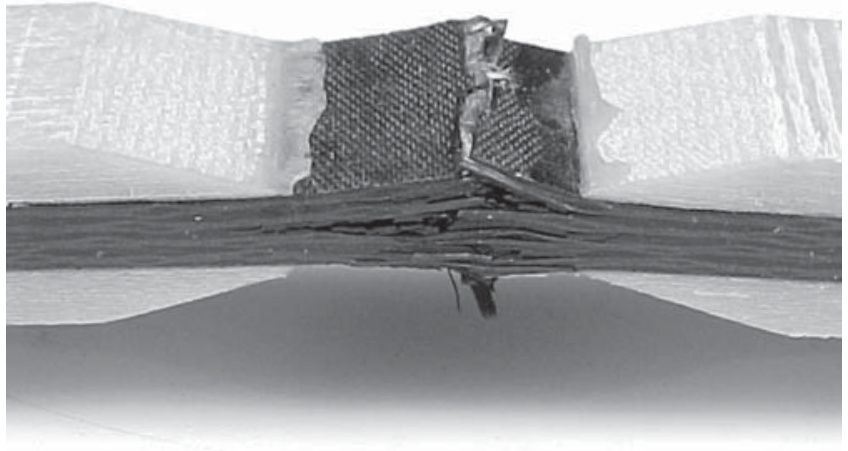

Figure 14. Conditioned F584/8HS laminate after compression test, showing "kink zones" and fracture.

ticization effect. The hygrothermal conditioning caused a decrease of the compressive strength results of approximately $7.7 \%$ for the F155/PW, $15.7 \%$ for the F155/8HS and 20.3\% for the F584/8HS in this property.

The mechanical property results of the carbon fabrics reinforced epoxy matrix laminates show that they are adequate materials for application in aeronautical industry.

The work presently in progress is looking for other properties, for example, to increase the impact strength of the composites (laminates). For this study is being used an epoxy resin modified with elastomer.

\section{Acknowledgments}

The authors acknowledge the financial support received from FAPESP and CNPq under grants 02/02057-5 and 303528/2003-6, respectively. The authors are grateful to Hexcel Composites and EMBRAER for supplying the test material.

\section{References}

1. Schwartz M M. Composite Materials: Properties, Nondestructive Testing, and Repair. v.1. New Jersey, USA. Prentice-Hall Inc. 1997.

2. Hayes B S, Gilbert E N, Seferis J C. Scaling complications of dual temperature cure resin prepreg systems in airplane part manufacture. Composites: Part A. 2000; (31):717-725.

3. Matthews F L, Rawlings R D. Composite Materials: Engineering and Science, 2.ed. Boca Raton. Woodhead Publishing Ltd and CRC Press; p. 470.1999

4. Baker A A, Callus P J, Georgiadis S, Falzon P J, Dutton, S E, Leong K H. An affordable methodology for replacing metallic aircraft panels with advanced composites. Composites: Part A. 2002; 33:687-696.

5. Pilato LA, Michno M J. Advanced Composite Materials. Berlin, Germany. Springer Verlag Berlin Heidelberg. 1994.

6. Ding Y Q, Yan Y, Mcllhagger R. Effect of impact and fatique loads on the strength of plain weave carbon-epoxy composites, Journal of Materials Processing Technology. 1995; 55:58-62.

7. Gao S-L, Kim J-K. Cooling rate influences in carbon fibre/PEEK composites. Part III: impact damage performance. Composites, Part A. 2001; 32:775-785.

8. Kim J, Shioya M, Kobayashi H, Kaneko J, Kido M. Mechanical properties of woven laminates and felt composites using carbon fibers. Part 1: in-plane properties. Composites Science and Technology. 2004; 64:2221-2229. 
9. Yang B, Kozey V, Adanur S, Kumar S. Bending, compression, and shear behavior of woven glass fiber-epoxy composites. Composites: Part B. 2000; 31:715-721.

10. Carlsson L A, Pipes R B. Experimental Characterization of Advanced Composite Materials. 2.ed., USA, Lancaster, Technomic Publishing; p. 81-91. 1997.

11. ASTM D790. Standard Test Methods for Flexure Properties of Unreinforced and Reinforced Plastics and Electrical Insulating Materials. American Society for Testing Materials, [CD-ROM].

12. Hull D Clyne T W. An Introduction to Composite Materials. 2. ed., Great Britain, Cambridge University Press; p.178-186. 1996.

13. Zhang Z, Liu Y, Huang Y, Liu L, Bao J. The effect of carbon-fiber surface properties on the electron-beam curing of epoxy-resin composites. Composites Science and Technology. 2002; 62:331-337.

14. Tanoglu M, Robert S, Heider D, McKnigth S H, Brachos V, Gillespie $\mathrm{Jr}$, J W. Effects of thermoplastic preforming binder on the properties of S2-glass fabric reinforced epoxy composites. International Journal of Adhesion \& Adhesives. 2001; 21(3):187-195.

15. ASTM D3410. Standard Test Method for Compressive Properties of Unidirectional or Crossply Fiber-Resin Composites. American Society for Testing and Materials; p.132-139. 1987.

16. Buehler F U, Seferis J C. Effect of reinforcement and solvent content on moisture absorption in epoxy composite materials. Composites: Part A. 2000; 31(7):741-748

17. Wang J -Y, Ploehn H J. Dynamic Mechanical Analysis of the effect of water on glass bead-epoxy composites. Journal of Applied Polymer Science. 1996; 59:345-357.

18. Ogi K, Kim H S, Maruyama T, Takao Y. The influence of hygrothermal conditions on the damage processes in quasi-isotropic carbon/epoxy laminates. Composites Science and Technology. 1999; 59(16):2375-2382.

19. Hexcel Composites. Resin systems for advanced composites. In: Catalog of Hexcel Composites. Pleasanton, USA. 2000.

20. Hexcel Composites. Types of reinforcement. [homepage on the Internet].
USA: About.com. [updated 2003 september 2; cited 2003 october 12]. Available from: http//www.hexcel.com.

21. ASTM D3171. Standard Test Methods for Fiber Content of Resin-matrix composites by Matrix Digestion. American Society for Testing and Materials. Philadelphia, PA; p. 122-124. 1982.

22. ASTM D2344. Standard Test Method for Apparent Interlaminar Shear Strength of Parallel Fiber Composites by Short-Beam Method. American Society for Testing and Materials; p. 43-45. 1984.

23. ASTM D5229. Standard Test Method for Moisture Absorption Properties and Equilibrium Conditioning of Polymer Matrix Composite Materials. American Society for Testing and Materia. 1992.

24. Varley R J, Hodgkin J H, Simon G P. Toughening of a trifunctional epoxy system. Part VI. Structure property relationships of the thermoplastic toughened system. Polymer. 2001; 42:3847-3858.

25. Owen M J. Thermosetting resins. In: Integrated Design and Manufacture using Fibre-Reinforced Polymeric Composites. Ed. by: M. J. Owen, V. Middleton and I. A. Jones. CRC Press LLC and Woodhead Publishing Limited, England; p. 30-46. 2000.

26. Jang B Z. Advanced Polymer Composites: Principles and Applications. ASM International, Materials Park, USA; p. 297. 1994.

27. Lafdi K, Wright MA. Carbon Fibers. In: Handbook of Composites. 2.ed., Great Britain. Ed. by S. T. Peters, Chapman \& Hall; p. 190-199. 1998.

28. Lee S H, Yerramalli C S, Waas A M. Compressive splitting response of glass-fiber reinforced unidirectional composites. Composites Science and Technology. 2000; 60:2957-2966.

29. Master J E. Basic Failure modes of continuous fiber composites. In: Engineered Materials Handbook. v. 1. Metals Park, OH:ASM; p. 781-785. 1987.

30. Choi H S, Ahn K J, Nam J -D, Chun H J. Hygroscopic aspects of epoxy/ carbon fiber composite laminates in aircraft environments. Composites: Part A. 2001; 32:709-720.

31. Vanlandingham M R, Eduljee R F, Gillespie J W Jr. Moisture diffusion in epoxy systems. Journal of Applied Polymer Science. 1999; 71:787-798. 